\title{
Effect of the Polymorphism of Tumor Necrosis Factor- $\alpha-308$ G/A Gene Promoter on the Susceptibility to Ulcerative Colitis: A Meta-Analysis
}

\author{
Zonghai Lu Lei Chen Hui Li Yanjun Zhao Lin Lin \\ Department of Gastroenterology, First Affiliated Hospital of Nanjing Medical University, Nanjing, China
}

\section{Key Words}

Tumor necrosis factor $\cdot$ Ulcerative colitis · Susceptibility · Meta-analysis

\begin{abstract}
Background: Ulcerative colitis (UC) is a complex polygenic disease in which gene-environment interactions are important. Some studies have reported that proinflammatory polymorphisms in tumor necrosis factor- $\alpha-308$ (TNF- $\alpha-308$ ) gene promoter (substitution $\mathrm{G} \rightarrow \mathrm{A}$, designated as TNF1 and TNF2) is associated with increased UC risk. However, the results of individual studies have been inconsistent. Methods: To investigate the inconsistent findings in studies of the association of the polymorphism of TNF- $\alpha-308$ gene promoter with susceptibility to UC, a systematic review of the published data was undertaken and a meta-analysis was performed. The MEDLINE database was searched for case-control studies published in English language journals from 1966 to November 2007. Data were extracted using standardized forms and odds ratios (OR) with $95 \%$ confidence intervals $(\mathrm{Cl})$ were calculated. Results: 15 eligible studies, 7 of Europeans, 2 of Americans, and 6 of Asians including 4 East Asians, were included in the meta-analysis. An association between UC and TNF2 allele was not found in the overall population (OR 1.28, 95\% Cl 0.84-1.96, $\mathrm{p}=0.25$ ). However,
\end{abstract}

stratification by ethnicity indicated that there was significant association between TNF2 allele and UC in East Asians (OR 2.27, 95\% Cl 1.08-4.77, $\mathrm{p}=0.03$ ). Conversely, there was no association between TNF2 allele and UC patients from the European (OR 0.85, 95\% Cl 0.42-1.71, $\mathrm{p}=0.65$ ) and Asian samples (OR 1.64, 95\% Cl 0.98-2.74, $\mathrm{p}=0.06)$. The OR for the TNF2/2+TNF2/1 genotype versus TNF1/1 genotype in samples overall and in each ethnic group showed a similar trend to those for the TNF2 allele. Conclusion: In East Asians, the TNF2 allele confers a significant risk for developing UC. There is no association between the polymorphism of TNF- $\alpha-308$ gene promoter and UC in Europeans.

Copyright $\odot 2008$ S. Karger AG, Basel

\section{Introduction}

Ulcerative colitis (UC) is a chronic inflammatory intestinal disease which diffusely affects the superficial mucosa of the colon and extends proximally from the anal verge up to the cecum [1]. The etiology of UC is complicated, and both genetic and environmental factors play important roles [2-4]. The genes predisposing to UC are likely to contain polymorphisms that modify function.

Tumor necrosis factor- $\alpha$ (TNF- $\alpha$ ) is a potent proinflammatory cytokine which plays an important role in

\section{KARGER}

Fax +41613061234 E-Mail karger@karger.ch www.karger.com (c) 2008 S. Karger AG, Basel 0012-2823/08/0781-0044\$24.50/0

Accessible online at:

www.karger.com/dig
Prof. Lin Lin

Department of Gastroenterology

First Affiliated Hospital of Nanjing Medical University

300 Guangzhou Road, Nanjing 210029 (China)

Tel. +86 258371 8836, ext. 6973, Fax +86 258367 4636, E-Mail lin9110@yahoo.cn 
Table 1. Characteristics of 15 publications included in meta-analysis of TNF- $\alpha-308$ polymorphism and UC susceptibility

\begin{tabular}{|c|c|c|c|c|c|c|}
\hline \multirow{2}{*}{$\begin{array}{l}\text { Study } \\
\text { (first author) }\end{array}$} & \multirow[t]{2}{*}{ Country } & \multirow{2}{*}{$\begin{array}{l}\text { UC/ } \\
\text { control, } \mathrm{n}\end{array}$} & \multirow{2}{*}{$\begin{array}{l}\text { TNF2 vs. TNF1 } \\
\text { OR }(95 \% \text { CI })\end{array}$} & \multirow{2}{*}{$\begin{array}{l}\text { TNF2/2+TNF2/1 vs. } \\
\text { TNF1/1, OR ( } 95 \% \text { CI) }\end{array}$} & \multicolumn{2}{|c|}{ Power $^{1}, \%$} \\
\hline & & & & & OR 1.5 & OR 2.0 \\
\hline Song, 2005 & China & $103 / 220$ & $4.59(2.02-10.39)$ & $4.63(1.99-10.80)$ & 30.1 & 72.0 \\
\hline Cao, 2006 & China & $110 / 292$ & $1.74(1.09-2.79)$ & $1.90(1.13-3.18)$ & 33.5 & 77.5 \\
\hline Santos, 2006 & Spain & $99 / 343$ & $1.36(0.88-2.12)$ & $1.41(0.85-2.32)$ & 32.4 & 75.9 \\
\hline Cantor, 2005 & Canada & $55 / 92$ & $1.23(0.67-2.26)$ & $1.24(0.61-2.51)$ & 17.0 & 42.9 \\
\hline Cucchiara, 2007 & Italy & $173 / 347$ & $1.97(1.24-3.12)$ & $1.86(1.12-3.08)$ & 45.4 & 90.4 \\
\hline Sashio, 2002 & Japan & $106 / 111$ & $5.14(1.71-25.44)$ & $5.11(1.66-15.74)$ & 24.3 & 60.9 \\
\hline Jesus, 2004 & Mexico & $80 / 99$ & $8.76(2.54-30.17)$ & $4.98(1.88-13.18)$ & 20.7 & 52.4 \\
\hline Balding, 2004 & Ireland & $108 / 389$ & $0.73(0.49-1.08)$ & $0.57(0.36-0.90)$ & 35.1 & 79.7 \\
\hline Bouma, 1996 & Netherlands & $89 / 54$ & $0.14(0.08-0.25)$ & $0.50(0.24-1.02)$ & 16.7 & 42.1 \\
\hline Martin, 2002 & Germany & $93 / 119$ & $0.73(0.40-1.34)$ & $0.70(0.37-1.33)$ & 23.6 & 59.3 \\
\hline Mittal, 2006 & India & $92 / 164$ & $0.93(0.65-1.34)$ & $0.60(0.23-1.53)$ & 26.0 & 64.5 \\
\hline Sykora, 2006 & Czech Republic & $36 / 82$ & $3.62(1.61-8.13)$ & $4.11(1.63-10.34)$ & 13.5 & 33.0 \\
\hline Vatay, 2003 & Hungary & $50 / 138$ & $0.46(0.22-0.97)$ & $0.45(0.20-1.01)$ & 17.9 & 45.2 \\
\hline Celik, 2006 & Turkey & $120 / 105$ & $1.10(0.59-2.05)$ & $1.13(0.58-2.21)$ & 25.0 & 62.3 \\
\hline Kim, 2003 & Korea & $91 / 200$ & $0.89(0.46-1.75)$ & $0.86(0.43-1.73)$ & 27.3 & 67.1 \\
\hline
\end{tabular}

$\mathrm{OR}=$ Odds ratio; $\mathrm{CI}=$ confidence interval; $1=\mathrm{G}, 2=\mathrm{A} .{ }^{1}$ Frequency of $\mathrm{A}=0.2, \alpha=0.05$, A: disease allele.

inflammatory and immune responses, including in UC [5-7]. TNF- $\alpha$ stimulates cytokine production, enhancing expression of adhesion molecules and increasing neutrophil activation. The TNF- $\alpha$ gene is located on chromosome 6, within the class III region of HLA. Several singlenucleotide polymorphisms have been identified in the promoter, a G (named TNF1 allele) to A (named TNF2 allele) substitution at position -308 [8], has been studied intensively. It is not clear whether the TNF- $\alpha-308$ promoter polymorphism has a functional significance, but some studies suggest that the TNF2 allele might have a small but significant association with greater levels of TNF transcription $[9,10]$.

A number of studies have assessed the association between the TNF- $\alpha-308$ promoter polymorphism and UC in different populations; however, the results are inconsistent and inconclusive [11-25]. Different methodologies have been used, but, in particular, most of the studies used a small sample size and it is therefore not surprising that there has been a lack of replication in the various studies. By using all the available published data to increase the statistical power, it was hypothesized that a meta-analysis might allow plausible candidate genes to be excluded and causative genes to be identified with reliability. We have therefore taken a meta-analysis in which all the published case-control studies are processed to confirm whether the polymorphisms of TNF- $\alpha-308$ gene promoter increased the risk of UC.

Effect of TNF- $\alpha-308$ Polymorphism on the Susceptibility to UC

\section{Methods}

\section{Study Selection}

The MEDLINE database was searched (last updated search being November 2007) using PubMed and Highwire search engines. The key words used were as follows: ulcerative colitis, tumor necrosis factor and polymorphism or variant or genotype. At the same time, we searched manually the reference lists of relevant publications for additional studies.

To be included in the meta-analysis, studies had to meet the following criteria: (1) the design had to be a case-control study; (2) the outcome had to be UC, and (3) there had to be at least two comparison groups (UC vs. control groups). Participants could be of any age. Studies were excluded if one of the following existed: (1) the design was based on family or sibling pairs; (2) the genotype frequency was not reported, or (3) there was insufficient information for extraction of data.

\section{Data Extraction and Inclusion Criteria}

A standard reporting form was used to abstract the data from each publication, which includes: first author's name, year of publication, country in which the study was carried out, ethnicity, age range of study subjects, and sample size. Data were extracted independently and in duplicate by two investigators. The results were compared and disagreements were resolved by consensus.

\section{Statistical Analysis}

The analysis was conducted in Review Manager 4.2.8. Analysis was performed for TNF2 (minor allele) versus TNF1 (common allele) and TNF2/2+TNF2/1 versus TNF1/1 genotype. These contrasts correspond to recessive and dominant effects of the TNF2 allele, respectively. The odds ratio (OR) and 95\% confidence interval (CI) were estimated for each study in a random-effects 
Table 2. Meta-analysis of the TNF- $\alpha-308$ gene polymorphism and UC association

\begin{tabular}{|c|c|c|c|c|c|c|c|}
\hline \multirow[t]{2}{*}{ Comparison } & \multirow[t]{2}{*}{ Population } & \multirow[t]{2}{*}{ Studies, $\mathrm{n}$} & \multicolumn{2}{|l|}{ Test of association } & \multicolumn{3}{|c|}{ Test of heterogeneity } \\
\hline & & & OR (95\% CI) & $\mathrm{p}$ & $\chi^{2}$ & $\mathrm{p}^{+}$ & $\mathrm{I}^{2}$ \\
\hline \multirow{4}{*}{$\begin{array}{l}\text { TNF2 } \\
\text { vs. TNF1 }\end{array}$} & Overall & 15 & $1.28(0.84-1.96)$ & 0.25 & 111.14 & $<0.00001$ & 0.874 \\
\hline & European & 7 & $0.85(0.42-1.71)$ & 0.65 & 70.96 & $<0.00001$ & 0.915 \\
\hline & Asian & 6 & $1.64(0.98-2.74)$ & 0.06 & 12.59 & 0.0007 & 0.765 \\
\hline & East Asian & 4 & $2.27(1.08-4.77)$ & 0.03 & 12.59 & 0.006 & 0.672 \\
\hline \multirow{4}{*}{$\begin{array}{l}\text { TNF2/2+ } \\
\text { TNF2/1 } \\
\text { vs. TNF1/1 }\end{array}$} & Overall & 15 & $1.33(0.91-1.95)$ & 0.14 & 64.60 & $<0.00001$ & 0.783 \\
\hline & European & 7 & $0.98(0.58-1.66)$ & 0.93 & 30.80 & $<0.001$ & 0.805 \\
\hline & Asian & 6 & $1.66(0.91-3.02)$ & 0.10 & 18.86 & 0.002 & 0.735 \\
\hline & East Asian & 4 & $2.32(1.08-4.96)$ & 0.03 & 12.10 & 0.007 & 0.752 \\
\hline
\end{tabular}

$\mathrm{OR}=$ Odds ratio; $\mathrm{CI}=$ confidence interval; $1=\mathrm{G}, 2=\mathrm{A}$.

${ }^{+} \mathrm{p}<0.05$ is considered statistically significant for $\chi^{2}$ statistics; $\mathrm{I}^{2}$ is interpreted as the proportion of total variation contributed by between-study variation.

model or in a fixed-effects model. Heterogeneity among studies was examined with the $\chi^{2}$-based $Q$ testing and $\mathrm{I}^{2}$ statistics. A p value $<0.05$ was considered significant for the $\chi^{2}$-based $Q$ testing and $\mathrm{I}^{2}$ was interpreted as the proportion of total variation contributed by between-study variation. If there was a significant heterogeneity $(\mathrm{p}<0.05)$, we selected a random-effects model to pool the data. If not, we selected a fixed-effects model to pool the data.

We estimated the expected power of each individual study as determined by the probability of detecting a true association between TNF- $\alpha-308$ promoter polymorphism and UC at the 0.05 level of significance, assuming OR of 1.5 and 2.0 for differences in allele frequency, and the minor (disease) allele frequency is of 0.2 . The power analysis was performed at http://calculators.stat. ucla.edu/powercalc/.

\section{Results}

\section{Studies Included in the Meta-Analysis}

A total of 15 relevant studies with TNF- $\alpha-308$ gene promoter polymorphisms and UC met the inclusion criteria [11-25]. Seven studies were excluded for the following reasons: data duplication $(\mathrm{n}=1)$ [26], no allele or genotyping frequency $(\mathrm{n}=4)$ [27-30], and analysis of the TNF- $\alpha-857$ polymorphism rather than TNF- $\alpha-308$ $(\mathrm{n}=2)[31,32]$.

These 15 studies consisted of 7 European [11-17], 6 Asian [18-23] which included 4 East Asian [20-23], and 2 American population samples [24, 25] (table 1). The allele and genotype frequency of the TNF- $\alpha-308$ gene promoter polymorphisms were extracted from all of the 15 studies. Because the inadequate sample populations were available for the American group, we performed ethnic- ity-specific meta-analysis only in the European, Asian and East Asian populations.

\section{Evaluation of TNF- $\alpha$-308 Gene Promoter}

Polymorphisms and Association with UC

Selected characteristics of 15 cases control studies for TNF- $\alpha-308$ gene promoter polymorphisms are summarized in table 1. Table 1 also shows the expected power of each individual study to reveal an association between this polymorphism and UC. Only 4 of the 15 studies used in the meta-analysis had more than $75 \%$ power to detect an effect of this size (table 1). The OR with 95\% CI of individual studies for the association of the TNF2 allele at the TNF- $\alpha$ locus and UC are shown in table 1. The studies from Europe (2), America (1) and Asia (3) showed significantly increased OR of the TNF2 allele, but 2 studies from Europe showed significantly decreased OR for the TNF2 allele.

A summary of meta-analysis for the TNF- $\alpha-308$ gene promoter polymorphisms with UC is shown in table 2. From the meta-analysis, an association between UC and the TNF2 allele was not found in the overall population (OR 1.28, 95\% CI 0.84-1.96, p = 0.25; fig. 1a). However,

Fig. 1. OR and 95\% CI of individual studies and pooled data for the association between TNF2 allele versus TNF1 allele and UC risk in overall (a) and subgroup populations (b) from Europe, Asia and East Asia. TNF2 was a risk factor for UC in East Asians, but not in Asians and Europeans. 


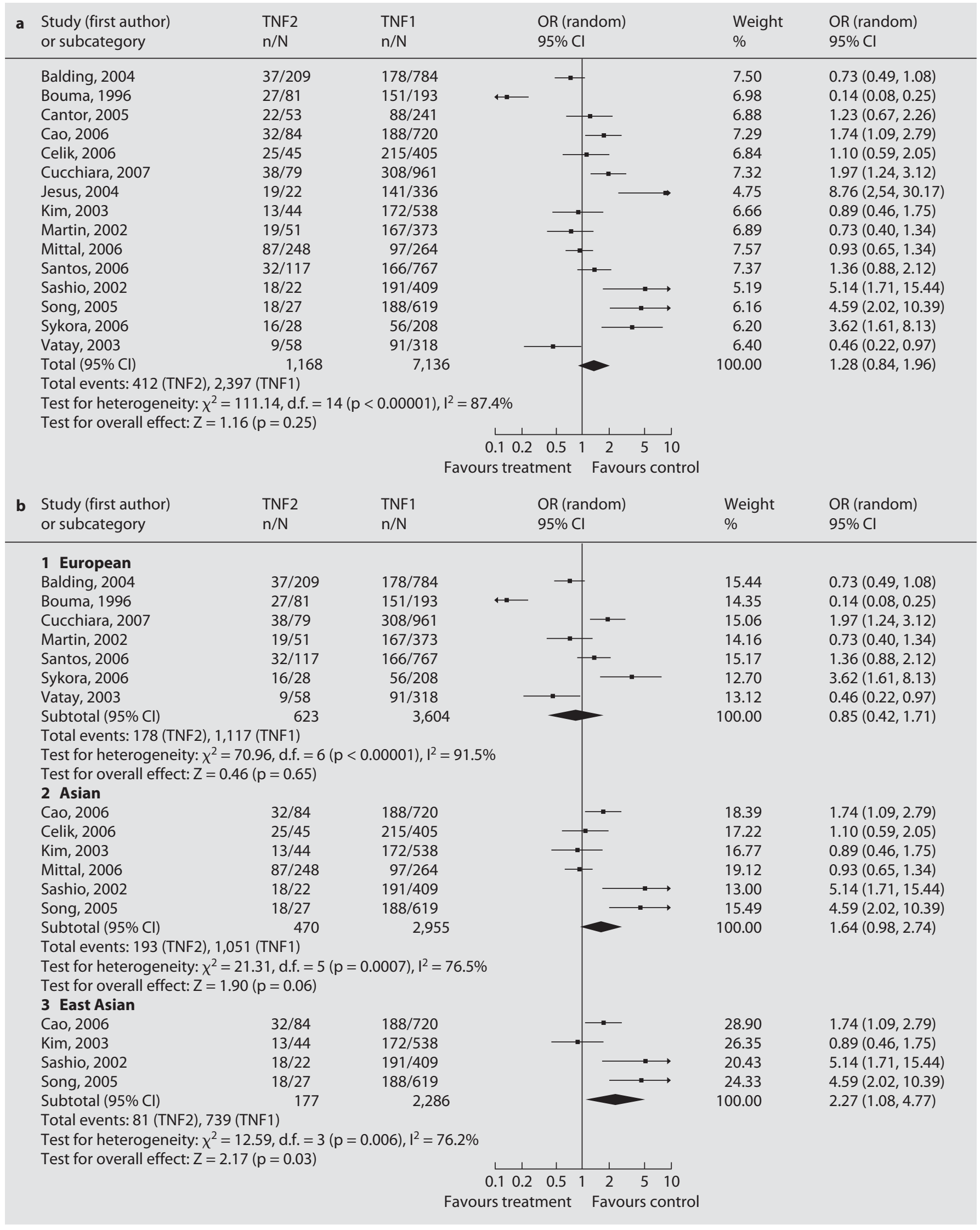




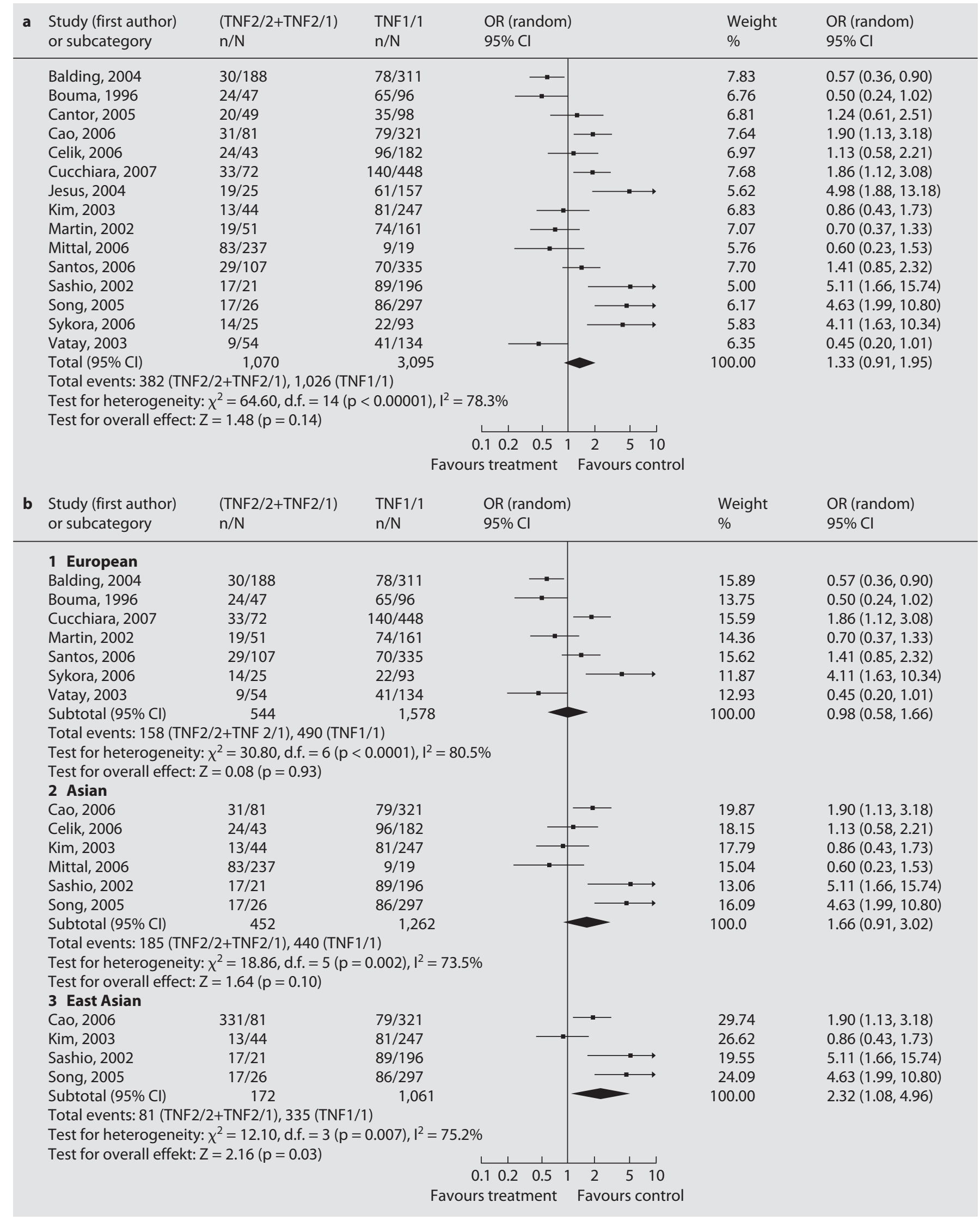


stratification by ethnicity indicates that the TNF2 allele was significantly associated with UC in East Asians (OR 2.27, 95\% CI 1.08-4.77, $\mathrm{p}=0.03$; fig. 1b). Conversely, no association was detected for the TNF2 allele with UC patients from the European (OR 0.85, 95\% CI 0.42-1.71, p = 0.65; fig. 2) and Asian samples (OR 1.64, 95\% CI 0.98 $2.74, \mathrm{p}=0.06$; fig. $1 \mathrm{~b}$ ). The total OR for the TNF2/2+ TNF2/1 genotype of the TNF- $\alpha-308$ promoter was 1.33 in the overall population (95\% CI $0.91-1.95, \mathrm{p}=0.14$; fig. 2a). Stratification by ethnicity indicates that the TNF2/2+TNF2/1 genotype was a risk factor for UC in East Asian (OR 2.32, 95\% CI 1.08-4.96, p = 0.03; fig. 2b), but not in Europeans (OR 0.98, 95\% CI 0.58-1.66, p = 0.93; fig. 2b) and Asians (OR 1.66, 95\% CI 0.91-3.02, $\mathrm{p}=$ 0.10 ; fig. $2 \mathrm{~b})$.

\section{Discussion}

TNF- $\alpha$ gene is located on chromosome 6 within the HLA class III region, telomeric to the class II and centromeric I region. Linkage of inflammatory disease has been demonstrated recently to this region which is situated on the short arm of chromosome 6 [33], and TNF- $\alpha-308$ gene polymorphism has been reported to be associated with several autoimmune disorders including UC [22]. The reports comparing TNF production from individual cells of bearing the TNF2 allele versus individuals with other alleles have generated conflicting results $[34,35]$. And studies of an association of TNF- $\alpha-308$ gene polymorphism with UC have also reported conflicting results [11-25]. This discrepancy among results is not surprising. Persistent difficulties in obtaining robust and replicable results in genetic effects are small, requiring studies with many thousands of subjects or meta-analysis to be detected.

Our meta-analysis showed no significant susceptibility from the TNF- $\alpha-308$ gene promoter polymorphism with UC in the overall population samples. Subsequently, a meta-analysis after stratification by ethnicity detected a significant association with the TNF- $\alpha$ polymorphism in the East Asian-derived samples, but not in European

Fig. 2. OR and $95 \%$ CI of individual studies and pooled data for the association between (TNF2/2+TNF2/1) genotype versus TNF1/1 genotype and UC risk in overall (a) and subgroup populations (b) from Europe, Asia and East Asia. TNF2/2+TNF2/1 was a risk factor for UC in East Asians, but not in Asians and Europeans.

Effect of TNF- $\alpha-308$ Polymorphism on the Susceptibility to UC samples. The available data supports that TNF- $\alpha-308$ gene promoter polymorphism in UC may be an ethnic population-specific risk factor, although the small number of East Asian-derived studies available to date reduces our confidence in this conclusion. The most powerful study to date came from East Asia [22], and 3 studies from East Asia have shown the same direction of the association, suggesting strong association of the TNF- $\alpha-308$ gene promoter polymorphism with UC in this ethnic population.

Meta-analysis of the TNF2 allele and TNF2/2+TNF2/1 genotype revealed a significant association with UC in East Asian data, but meta-analyses of the TNF2 allele and TNF2/2+TNF2/1 genotype showed no significant association in Asian data. The OR of the TNF2 allele and TNF2/2+TNF2/1 genotype increased in Asian data, although they did not reach statistical significance. This finding may be explained due to low statistical power based on the rare frequency of the TNF2 allele. Taken together, these findings suggest that TNF- $\alpha-308$ gene promoter polymorphism may confer a risk for UC in East Asians. Since only 4 studies were included, this result must be interpreted with caution. More East Asian studies should be recruited to clarify this possible association.

Interestingly, the meta-analysis did not reveal any association of the TNF- $\alpha-308$ gene promoter polymorphism with UC in Europeans. The findings of different associations according to ethnicity are somewhat surprising. An explanation is needed to do why the TNF- $\alpha$ 308 gene promoter polymorphism is not association with UC in European populations and plays a different role in different ethnic populations. First, genetic heterogeneity for UC may exist in different populations. Second, clinical heterogeneity may explain the discrepancy. The differences in UC populations may cause different results. Third, different linkage disequilibrium (LD) patterns may contribute to the discrepancy. This polymorphism may be in LD with a nearby causal variant in one ethnic group, but not in another. Fourth, the difference might arise from chance, such as I error. A type I error occurs when there really is no difference (association, correlation) overall, but random sampling caused your data to show a statistically significant difference (association, correlation). Because the patient numbers are far outweighed by the controls and the TNF2 allele is relatively rare in East Asian populations, the possibility of a type I error is relatively high. Fifth, TNF polymorphisms may occur with distinct patterns in ethnically distinct populations [36].

Digestion 2008;78:44-51 
Some limitations should be discussed in this metaanalysis. First, publication bias and heterogeneity may be present, influencing the result of meta-analysis. We could not construct a funnel plot for each meta-analysis due to small numbers of studies, and there was significant heterogeneity among studies in populations of European descent. Second, the numbers of subjects and studies included in the ethnicity-specific meta-analysis were small. There were only 4 studies for East Asians, and which may not have enough persuasion to show an association between TNF- $\alpha-308$ gene promoter polymorphism and UC in each ethnic group. Third, although the available genetic data may implicate the TNF- $\alpha-308$ gene promoter polymorphism as a risk factor of UC susceptibility in East Asians, studies from other ethnic groups are needed to do whether the TNF- $\alpha-308$ gene promoter polymorphism confers a risk for UC in other populations or not. We could not do meta-analyses in American ethnic groups due to no or a small number of studies. Further studies on the association of the TNF- $\alpha-308$ gene promoter polymorphism and UC are needed to do in other ethnic populations.

Recently, one study reported a strong association between TNF- $\alpha$-308 gene promoter polymorphism and UC-associated CRC [37]. Our meta-analysis demonstrates that the TNF- $\alpha-308$ gene promoter polymorphism may be a significant risk factor for UC in East Asians. So we discuss what consequences this would have on the as- sociation reported in the present study between the same variant and UC in East Asia. The TNF- $\alpha-308$ gene promoter polymorphism is associated with higher expression in vitro and in vivo of TNF- $\alpha$ [38]. TNF- $\alpha$ plays an important role in inflammatory and immune responses, including in UC [5-7]. Inflammation is a complex response, at the cell and tissue level, to a variety of stimuli, including heating, trauma, viral/bacterial infections, and endotoxemia. A persistent state of inflammation is thought to produce chronic damage leading to lung cancer [39], bladder cancer [40], gastric cancer [41], and CRC [42]. Inflammation favors tumorigenesis by stimulating angiogenesis [43], damaging DNA [43], and chronically stimulating cell proliferation [44]. Proinflammatory genes have been shown also to be important for the maintenance and progression of CRC $[45,46]$. So we presume that TNF- $\alpha-308$ G-A in UC may also act as CRC disease risk modifiers in East Asia, but there is no information about the relationship between the TNF- $\alpha$-308G-A polymorphism and colorectal cancer in East Asia and further studies are necessary to confirm the above result.

Our meta-analysis demonstrates that the TNF- $\alpha-308$ gene promoter polymorphism may be a significant risk factor for UC in East Asians, but it is not likely to confer susceptibility to UC in Europeans. More studies in various ethnic groups are necessary in order to determine the role of TNF- $\alpha-308$ gene promoter polymorphism in UC.

\section{References}

-1 Shen EH, Das KM: Current therapeutic recommendations: infliximab for ulcerative colitis. J Clin Gastroenterol 2004;38:741745.

$\checkmark 2$ Hanauer SB: Inflammatory bowel disease: epidemiology, pathogenesis, and therapeutic opportunities. Inflamm Bowel Dis 2006;12: S3-S9.

$\checkmark 3$ Mathew CG, Lewis CM: Genetics of inflammatory bowel disease: progress and prospects. Hum Mol Genet 2004;13:161-168.

$\checkmark 4$ Bonen DK, Cho JH: The genetics of inflammatory bowel disease. Gastroenterology 2003;124:521-536.

5 Reimund JM, Wittersheim C, Dumont S, et al: Mucosal inflammatory cytokine production by intestinal biopsies in patients with ulcerative colitis and Crohn's disease. J Clin Immunol 1996;16:144-150.

6 Braegger CP, Nicholls S, Murch SH, et al: Tumour necrosis factor- $\alpha$ in stool as a marker of intestinal inflammation. Lancet 1992;339: 89-91.
7 Murch SH, Lamkin VA, Savage MO, et al: Serum concentrations of tumour necrosis factor- $\alpha$ in childhood chronic inflammatory bowel disease. Gut 1991;32:913-917.

$\checkmark 8$ Wilson AG, di Giovine FS, Blakemore AI, et al: Single base polymorphism in the human tumour necrosis factor- $\alpha$ gene detectable by Ncol restriction of PCR product. Hum Mol Genet 1992;1:353.

-9 Louis E, Franchimont D, Piron A, et al: Tumour necrosis factor (TNF) gene polymorphism influences TNF- $\alpha$ production in lipopolysaccharide-stimulated whole blood cell culture in healthy humans. Clin Exp Immunol 1998;113:401-406.

10 Bouma G, Crusius JB, Oudkerk PM, et al: Secretion of tumour necrosis factor- $\alpha$ and lymphotoxin- $\alpha$ in relation to polymorphisms in the TNF genes and HLA-DR alleles. Relevance for inflammatory bowel disease. Scand J Immunol 1996;43:456-463.
11 Cuccchiara S, Latiano A, Palmieri O, et al: Polymorphisms of tumor necrosis factor- $\alpha$ but not MDR1 influence response to medical therapy in pediatric-onset inflammatory bowel disease. J Pediatr Gastroenterol Nutr 2007;44:171-179.

12 Santos P, Suarez A, Rivas L, et al: TNF- $\alpha$ and IL-10 gene polymorphisms in inflammatory bowel disease: association of -1082 AA low producer IL-10 genotype with steroid dependency. Am J Gastroenterol 2006;101:10391047.

13 Sykora J, Subrt I, Dedek P, et al: Cytokine tumor necrosis factor- $\alpha$ A promoter gene polymorphism at position-308 $\mathrm{G} \rightarrow \mathrm{A}$ and pediatric inflammatory bowel disease: implication in ulcerative colitis and Crohn's disease. J Pediatr Gastroenterol Nutr 2006, 42:479-487.

$>14$ Balding J, Livingstone W, Conroy J, et al: Inflammatory bowel disease: the role of inflammatory cytokine gene polymorphism. Mediators Inflamm 2004;13:181-187. 
15 Vatay A, Bene L, Kovacs A, et al: Relationship between the tumor necrosis- $\alpha$ polymorphism and the serum C-reaction protein levels in inflammatory bowel disease. Immunogenetics 2003;55:247-252.

-16 Martin K, Radlmayr M, Borchers R, et al: Candidate genes colocalized to linkage regions in inflammatory bowel disease. Digestion 2002;66:121-126.

-17 Bouma G, Xia B, Crusius B, et al: Distribution of four polymorphisms in the tumour necrosis factor genes in patients with inflammatory bowel disease. Clin Exp Immunol 1996;103:391-396.

-18 Celik Y, Dagli U, Kilic Y, et al: Cytokine gene polymorphisms in Turkish patients with inflammatory bowel disease. Scand J Gastroenterol 2006;41:559-565.

19 Mittal D, Manchanda P, Bid H, et al: Analysis of polymorphisms of tumor necrosis factor$\alpha$ and polymorphic xenobiotic-metabolizing enzymes in inflammatory bowel disease: study from Northern India. Gastroenterology 2006;10:1440-1746.

>20 Cao Q, Zhu Q, Wu ML, et al: Genetic susceptibility to ulcerative colitis in the Chinese Han ethnic population: association with TNF polymorphism. Chin Med J 2006;119: 1198-1203.

-21 Song Y, Wu KC, Zhang L, et al: Correlation between a gene polymorphism of tumor necrosis factor and inflammatory bowel disease. Chin J Dig Dis 2005;6:170-174.

-22 Sashio H, Tamura K, Ito R, et al: Polymorphisms of the TNF gene and the TNF receptor superfamily member $1 \mathrm{~B}$ gene are associated with susceptibility to ulcerative colitis and Crohn's disease, respectively. Immunogenetics 2002;53:1020-1027.

$\checkmark 23$ Kim T, Byeong G, Hyoung D, et al: Tumor necrosis factor- $\alpha$ and IL-10 gene polymorphisms in Korean patients with inflammatory bowel disease. Korean J Gastroenterol 2003;42:377-386.

24 Cantor M, Nickerson P, Bernstein C, et al: The role of cytokine gene polymorphisms in determining disease susceptibility and phenotype in inflammatory bowel disease. Am J Gastroenterol 2005;100:1134-1142.
25 Yamamoto-Furusho JK, Uscanga LF, Vargas-Alarcón G, et al: Polymorphisms in the promoter region of tumor necrosis factor- $\alpha$ and the HLA-DRB1 locus in Mexican Mestizo patients with ulcerative colitis. Immunol Lett 2004;95:31-35.

26 Bouma G, Crusius J, Gonzalez M, et al: Genetic markers in clinically well-defined patients with ulcerative colitis. Clin Exp Immunol 1999;115:294-300.

27 van Heel DA, Udalova IA, De Silva AP, et al: Inflammatory bowel disease is associated with a TNF polymorphism that affects an interaction between the OCT1 and NF- $\mathrm{OB}$ transcription factors. Hum Mol Genet 2002; 11:1281-1289.

28 Koss K, Satsangi J, Fanning GC, et al: Cytokine (TNF- $\alpha$, LT- $\alpha$ and IL-10) polymorphisms in inflammatory bowel diseases and normal controls: differential effects on production and allele frequencies. Genes Immun 2000;1:185-190.

29 Hirv K, Seyfarth M, Uibo R, et al: Polymorphisms in tumour necrosis factor and adhesion molecule genes in patients with inflammatory bowel disease: association with HLA-DR and -DQ alleles and subclinical markers. Scand J Gastroenterol 1999;34: 1025-1032.

30 Louis E, Satsangi J, Roussomoustakaki M, et al: Cytokine gene polymorphisms in inflammatory bowel disease. Gut 1996;39:705-710.

-31 Fidder H, Heijmans R, Chowers Y, et al: TNF-857 polymorphism in Israeli Jewish patients with inflammatory bowel disease. In J Immunogenet 2006;33:81-85.

32 Tremelling M, Waller S, Bredin F, et al: Genetic variants in TNF- $\alpha$ but not DLG5 are associated with inflammatory bowel disease in a large United Kingdom cohort. Inflamm Bowel Dis 2006;12:178-184.

33 Hampe J, Shaw SH, Saiz R, et al: Linkage of inflammatory bowel disease to human chromosome 6p. Am J Hum Genet 1999;65:16471655.

34 Bayley JP, de Rooij H, van den Elsen PJ, et al: Functional analysis of linker-scan mutants spanning the $-376,-308,-244$, and -238 polymorphic sites of the TNF- $\alpha$ promoter. Cytokine 2001;14:316-323.
35 Uglialoro AM, Turbay D, Pesavento PA, et al: Identification of three new single nucleotide polymorphisms in the human tumor necrosis factor- $\alpha$ gene promoter. Tissue Antigens 1998;52:359-367.

36 Baena A, Leung JY, Sullivan AD, et al: TNF$\alpha$ promoter single nucleotide polymorphisms are markers of human ancestry. Genes Immun 2002;3:482-487.

37 Suchy J, Klujszo-Grabowska E, Kladny J, et al: Inflammatory response gene polymorphisms and their relationship with colorectal cancer risk. BMC Cancer 2008;8:112.

38 Wilson AG, Symons JA, McDowell TL, et al: Effects of a polymorphism in the human tumor necrosis factor- $\alpha$ promoter on transcriptional activation. Proc Natl Acad Sci USA 1997;94:3195-3199.

39 Mayne ST, Buenconsejo J, Anderich DT: Previous lung disease and risk of lung cancer among men and women nonsmokers. Am J Epidemiol 1999;149:13-20.

40 Badawi AF, Mostafa MH, Probert A, et al: Role of schistosomiasis in human bladder cancer: evidence of association, aetiological factors, and basic mechanisms of carcinogenesis. Eur J Cancer Prev 1995;4:45-59.

$\checkmark 41$ Williams MP, Pounder RE: Helicobacter $p y$ lori: from the benign to the malignant. Am J Gastroenterol 1999;94:S11-S16.

42 Rhodes JM, Campbell BJ: Inflammation and colorectal cancer: IBD associated and sporadic cancer compared. Trends $\mathrm{Mol} \mathrm{Med}$ 2002;8:10-16

43 Jackson JR, Seed MP, Kircher CH, et al: The codependence of angiogenesis and chronic inflammation. FASEB J 1997;11:457-465.

44 Phoa N, Epe B: Influence of nitric oxide on the generation and repair of oxidative DNA damage in mammalian cells. Carcinogenesis (Lond) 2002;23:469-475.

45 Nakajima N, Kuwayama H, Ito Y, et al: Helicobacter pylori, neutrophils, interleukins, and gastric epithelial proliferation. J Clin Gastroenterol 1997;25(suppl 1):S198-S202.

46 Eberhart CE, Coffey RJ, Radhika A, et al: Upregulation of cyclooxygenase 2 gene expression in human colorectal adenomas and adenocarcinomas. Gastroenterology 1994;107: $1183-1188$ 